\title{
Docosahexaenoic acid and the preterm infant
}

Stephanie L. Smith ${ }^{1 *}$ and Christopher A. Rouse $e^{1,2}$

\begin{abstract}
Docosahexaenoic acid (DHA) is a long chain poly-unsaturated fatty acid (LCPUFA) that has a role in the cognitive and visual development, as well as in the immune function of newborns. Premature infants are typically deficient in DHA for several reasons, to include fetal accretion of DHA that typically occurs during the third trimester. These premature infants are reliant on enteral sources of DHA, most commonly through breast milk. The DHA content in breast milk varies in direct correlation with maternal DHA intake and mothers consuming a Western diet typically have lower levels of DHA in their breast milk. Maternal DHA supplementation and direct supplementation of DHA to the infant has been tried successfully but there are still conflicting results on the optimal dosage and method of delivery of DHA to the infant. This has led to inconsistent results in trials evaluating the effects of DHA supplementation to the preterm infant in terms of cognitive and immunological outcomes. While short-term benefits have been seen in several studies, long-term benefits are not consistent. Future studies continue to be needed to optimize DHA intake in our premature infants.
\end{abstract}

Keywords: Docosahexaenoic acid, Preterm infants, DHA supplementation, Breast milk, Inflammation, Neurodevelopment

\section{Background}

Docosahexaenoic acid (DHA) is a long chain polyunsaturated fatty acid (LCPUFA) that has a role in the cognitive and visual development, as well as in the immune function of newborns [1]. DHA is derived from $\alpha$-linolenic acid (ALA), an essential omega-3 fatty acid, through the enzyme $\boldsymbol{\Delta} \mathbf{6}$-desaturase [1]. ALA, along with its omega-6 counterpart linoleic acid (LA), are essential fatty acids that must be obtained from the diet as the human body is unable to synthesize them. CLA is the most common essential fatty acid consumed in the Western diet and can be found in vegetable oils, nuts and seeds. ALA is commonly found in flaxseed, walnuts and soy while DHA is found in fatty fishes such as salmon and tuna. While there is no consensus on the recommended DHA intake for pregnant or lactating women, several organizations, including the March of Dimes, American Academy of Pediatrics, and the Food and Agriculture Organization of the United Nations agree that pregnant and lactating women should have a minimal intake of 200-300 mg of DHA per day [2].

\footnotetext{
* Correspondence: Stephanie.I.smith230.mil@mail.mil

${ }^{1}$ Uniformed Services University of Health Sciences, 4301 Jones Bridge,

Bethesda, MD 20814, USA

Full list of author information is available at the end of the article
}

However, it is uncommon for women eating a Western diet to consume the recommended amount of DHA. A study published in 2017 by Nordgren et al. focused on evaluating the omega- 3 fatty acid intake in pregnant women as well as women of childbearing age in the United States [3]. The authors found that DHA intake in both pregnant and non-pregnant women was well below the recommended minimal intake of $200-300 \mathrm{mg} /$ day [3]. On average, a pregnant women's DHA intake in the United States was only $66 \mathrm{mg} /$ day and only $9.0 \%$ of women took DHA supplements during pregnancy [3]. Lower levels of DHA intake were correlated with lower economic status and education [3]. In addition, DHA crosses the placenta with the highest fetal accretion rates of LA, AA and DHA occur in the last 5 weeks of pregnancy [4]. Fetuses born to women who consume a typical Western diet have a DHA accretion rate of approximately $42-67 \mathrm{mg} /$ day in the last trimester, though this rate may not be ideal based on the low DHA intake and high LA intake of the Western diet $[4,5]$.

Following delivery, infants rely on enteral sources to meet their DHA requirement, whether through breast milk or formula. The DHA content of breast milk is correlated to maternal intake of DHA. To add to this, obesity is becoming more prevalent in the United States 
and has an effect on the omega- 3 fatty acids in breast milk [6]. Breast milk analyzed from obese mothers with BMI $>30 \mathrm{~kg} / \mathrm{m}^{2}$, was significantly lower in long-chain n3 FA and had a higher $n-6: n-3$ ratio. These findings were also seen in the plasma of breastfed neonates of obese mothers [6]. The $n-3$ concentration, which includes the concentration of DHA, in the breast milk of obese mothers could be improved by enrolling the mothers into a clinic for weight control and dietary support [6]. Vegetarian and vegan diets are also becoming more prevalent in today's society and it is also crucial to consider these diets' effects on DHA. Sanders reviewed published studies on the DHA status in vegetarians and vegans and found a lower DHA status in vegetarians and vegans compared to omnivores [7]. The concentration of DHA in breast milk is important because of DHA's contribution to brain and visual development as well as its affect on the immune system, which is vital for the premature infant. The objective of this paper is to review DHA and the premature infant looking specifically at: 1 ) DHA supplementation and its effect on breast milk; 2) DHA and the premature infant; 3) DHA and its effect on the neurodevelopment in the premature infant; and 4) DHA and its effect on the immune response in the premature infant.

\section{DHA and Breast milk}

Following delivery, infants become reliant on an enteral source of DHA, commonly through maternal breast milk. DHA content in breast milk is affected by several factors including maternal nutrition, gestational age at delivery, genetics, and the stage of lactation. The DHA content in breast milk varies in direct correlation with maternal DHA intake. The worldwide mean DHA concentration of breast milk is $0.32 \pm 0.22 \%$ (mean \pm standard error) [8]. Mothers who have the highest DHA concentration in their breast milk typically live in coastal areas such as the Canadian Artic, Japan and the Dominican Republic, as these areas have high seafood intake [8]. These locales have DHA concentrations ranging from $0.6 \%-1.4 \%$ [8]. Jackson and Harris examined evidence toward obtaining a goal for DHA concentration in breast milk and suggested that $0.3 \%$ is a reasonable initial target as it provides some improvement over the typical Western diet DHA breast milk level of 0.2\% [9]. Other studies have shown that it is possible to raise the DHA concentration in breast milk by maternal supplementation $[10,11]$. Dunstan et al. demonstrated that women who were supplemented with fish oil starting in pregnancy had a significantly higher DHA level in their breast milk over the first 6 postpartum weeks compared to controls [11]. Another study randomized lactating mothers to receiving a placebo, $200 \mathrm{mg}$ of DHA daily, or $400 \mathrm{mg}$ of DHA daily and compared DHA concentrations in breast milk [10]. The authors found that not only was the DHA content of breast milk higher in the high dose DHA group but that after 6 weeks of maternal supplementation the infants in the high maternal dose DHA group also had the lowest $n-6: n-3$ ratio in their plasma [10]. This study concluded that maternal supplementation with DHA can help increase DHA concentration in breast milk and thus increase the amount of DHA that infants receive. Gestational age and stage of lactation has also been shown to have an effect on DHA content of breast milk. Breast milk from mothers who delivered preterm had a significantly higher initial DHA content compared to mothers who delivered at term [12]. DHA has also been shown to significantly decrease in breast milk over the first month of lactation in both term and preterm human milk samples [12]. While DHA decreases in breast milk over the first month of lactation, total fat, LA and ALA tend to increase [13]. Lastly, genetics can also contribute to the DHA content of breast milk. Fatty acid desaturase (FADS) 1 and FADS2 code the enzymes $\Delta 5$-desaturase and $\triangle 6$-desaturase that are involved in the synthesis of ARA, EPA and DHA [14]. There is an association between maternal FADS genotype and the DHA content in breast milk with certain genotypes leading to a lower proportion of DHA in breast milk regardless of increased omega-3 intake $[14,15]$.

Donor breast milk is a significant component of nutrition for the premature infant and has been shown to have low amounts of DHA due to maternal diet as well as donor milk frequently coming from a later stage of lactation [16-19]. There is a large variance in DHA content in donor breast milk obtained through various donor milk banks across the United States [16]. DHA levels were found to vary from $0.07 \%$ to $0.2 \%$ in various studied United States milk banks [16]. A recent crosssectional sample of five donor breast milk banks (Ohio, Michigan, Texas, Colorado, and California) found that the average DHA concentration in donor milk was $7.1 \mathrm{mg} / 100 \mathrm{ml}$ which would provide preterm infants a DHA intake much lower than the fetal accretion rate of $42-67 \mathrm{mg} /$ day in the third trimester [17, 20, 21]. Another study by Valentine et al. evaluating DHA concentration in donor breast milk in Ohio also found a low donor milk DHA concentration of $\sim 0.1 \%$ [18]. In a subsequent study, Valentine et al. demonstrated that supplementing breast milk donors with $1 \mathrm{~g}$ of DHA daily increased the absolute milk concentration of DHA in donor breast milk to 4 times as high as the control group after 4 days of supplementation [19]. Based on an estimated intake of $150 \mathrm{ml} / \mathrm{kg} /$ day of donor milk in the preterm infant, the donor breast milk obtained from mothers receiving this DHA supplementation regimen would meet the expected intrauterine accretion levels for the preterm infant [19]. More recently, liquid human 
milk fortifier added to breast milk has been shown to increase the DHA content of breast milk [22]. Fortifier, with a DHA concentration of $\sim 0.15 \%$, can increase the level of DHA in the breast milk to $0.29 \%$. This is considerably closer to the world wide mean DHA level of $0.32 \%$, though still falls short of the intrauterine accretion rate. Per Lapillonne et al., milk containing a DHA concentration of $\sim 0.8 \%$ given at $150 \mathrm{ml} / \mathrm{kg} /$ day provides $45 \mathrm{mg} / \mathrm{kg} /$ day of DHA which is very similar to the intrauterine accretion rate [13].

Breast and donor milk obtained from mothers eating a Western diet typically have low concentrations of DHA that is below the worldwide mean of $0.32 \%$. By giving DHA supplements to mothers, it is possible to raise the DHA concentration of breast milk. Alternatively, for donor breast milk, where the milk is obtained from a later stage of lactation, using liquid human milk fortifier that contains DHA also raises DHA concentration level closer to the worldwide mean. This could potentially be vital for premature infants who typically are deficient in DHA.

\section{DHA and preterm infants}

While DHA is important to the term infant, it is particularly critical to the premature infant who is delivered early in or prior to the third trimester. Overall, fetal DHA accretion is estimated to be $10 \mathrm{~g}$, with the majority being acquired in the third trimester. [23]. The placenta aids with DHA accretion by allowing for preferential transfer of DHA over other fatty acids including LA and ALA [23]. As previously stated, the intrauterine accretion rate of DHA during the third trimester is approximately $42-67 \mathrm{mg} /$ day or $\sim 43 \mathrm{mg} / \mathrm{kg} /$ day $[4,5,24]$. This increase in DHA accretion in the third trimester coincides with brain and retina maturation [25]. DHA intake during pregnancy is not only important to ensure the fetus obtains adequate levels, but a systematic review by Kar et al. also showed that omega-3 fatty acids decrease the risk of delivery prior to 34 weeks by $58 \%$ [26]. Per Shireman et al., in a post-hoc analysis of their KUDOS study that showed a daily DHA intake of $600 \mathrm{mg}$ led to decrease length of hospitalization for the infant; thus having mothers take daily DHA could lead to cost savings for the health care system [27].

Premature infants are typically deficient in DHA for several reasons including missing the in utero accumulation of DHA in the third trimester, their inability to convert precursor fatty acids to DHA in large amounts, and deficient postnatal DHA intake [16]. Infants delivered at the lowest gestational ages are at the highest risk for DHA deficiencies [28]. De Rooy et al. published a study that evaluated the levels of DHA in extremely premature infants receiving standard care [29]. This longitudinal study evaluated omega- 6 and omega- 3 intake from all sources in infants $<28$ weeks. The authors showed that the total amount of DHA that infants received at the end of 6 weeks represented only $36.6 \%$ of DHA that they would have received in utero [29]. Extremely low birth weight infants who are exposed to IV lipids for a prolonged time also have a significant decline in their DHA levels [30]. This decline in DHA was seen when evaluating RBC DHA levels and was more significant in ELBW infants who received intravenous lipids for greater than 28 days [30]. This is not surprising as Intralipid, the lipid emulsion commonly used in the United States, is virtually barren of DHA and was originally created for adults who have a greater capability of converting DHA from its precursor [31]. As breast milk typically does not have the quantity of DHA needed to make up for the deficiency in DHA in preterm infants, researchers have studied other ways to increase DHA levels in infants.

Collins et al. examined the effects of providing infants delivered at $<33$ weeks different doses of DHA [32]. Infants were randomized to receive $40 \mathrm{mg} / \mathrm{kg} / \mathrm{day}$, $80 \mathrm{mg} / \mathrm{kg} /$ day or $120 \mathrm{mg} / \mathrm{kg} /$ day of DHA orally for 28 days with the primary outcome being erythrocyte phospholipid DHA levels [32]. The authors found that supplementing infants with $120 \mathrm{mg} / \mathrm{kg} /$ day of DHA prevented the drop in DHA typically seen in premature infants at this age [32]. The benefit of this oral emulsion was that it allowed infants to receive a larger amount of DHA early on than what they would receive from breast milk, even from breast milk obtained from mothers taking supplementation. While this study discontinued supplements at 28 days, a study performed by Baack et al. randomized preterm infants to receive a DHA supplement or from the first week of life until term or discharge [33]. Infants in the DHA supplement group received $50 \mathrm{mg} /$ day of DHA to match in utero DHA accretion rates. While DHA supplementation did significantly increase DHA levels in infants, the DHA levels at discharge in supplemented preterm infants remained significantly lower than term infant values [33]. Another recent study looking at delivering DHA via the buccal method found that this method did not alter DHA levels after 8 weeks of supplementation [34].

While term infants can achieve adequate DHA levels in breast milk through maternal supplementation, preterm infants struggle to overcome their DHA deficit. While directly supplementing preterm infants, as shown by both Collins et al. and Baack et al., does successfully increase their DHA level, the optimal amount of supplementation still needs to be determined [32, 33].

\section{DHA and cognitive/visual outcomes in preterm infants}

DHA is one of the most abundant LCPUFAs in the brain and has an important role in brain development including roles in neurotransmission and neurogenesis [35-37]. It is 
also found in high levels in the visual system, especially in rod photoreceptors and $M$ retinal ganglion cells [38]. From reviews of previous studies, the most consistent benefit from DHA supplementation was seen in earlier premature infants with lower birthweights, typically $<1500 \mathrm{~g}$, as these infants missed the majority of the third trimester with the highest fetal accretion rates of DHA. Therefore, a focus of DHA research has been to explore its role on cognitive and visual outcomes in the premature infant.

Previous studies have examined the association between DHA levels in the premature infant and cognitive outcomes. Tam et al. observed a cohort of 60 preterm infants between 24 and 32 weeks gestational age and noted an association between higher early red blood cell DHA levels and a decrease in both the incidence and severity of intraventricular hemorrhage (IVH) [39]. The authors showed that a $1 \%$ increase in early postnatal DHA was associated with a 4.3 fold decrease in the odds of intraventricular hemorrhage [39]. At 30-36 months corrected age (mean age of 33 months corrected), neurodevelopment outcome was able to be assessed in 45 of the 60 enrolled infants using the Bayley Scales of Infant Development, 3rd edition (BSID-3). The study showed an association with higher early DHA levels and improved developmental outcome at 30-36 months old that was not fully explained by the decreased risk of IVH [39]. Sabel et al. performed a longitudinal study on the development of premature infants at $3,6,10$ and 18 months corrected age using the Bayley's Scales of Infant Development, Second Edition (BSID-II) [40]. They found that in the initial 6 months, developmental scores were positively associated with breast milk DHA concentration [40]. Development was positively associated with DHA and negatively associated with $n-6$ fatty acids up to 18 months of age [40]. While these studies looked at the association between infant DHA level and cognitive outcome, there have been several studies evaluating the effects of DHA supplementation in premature infants on cognitive outcomes.

The DHA for the Improvement of Neurodevelopmental Outcome in preterm infants (DINO) trial was an Australian trial that randomized premature infants delivered at $<33$ weeks gestation to a high-DHA or standardDHA diet until they reach 40 weeks corrected age [41]. Mothers of infants in the high-DHA group took 6 capsules daily, containing DHA-rich tuna oil and the mothers of infants in the standard-DHA diet received placebo soy capsules. When analyzing the breast milk of the two groups, the high-DHA group had milk with a mean DHA concentration of $0.85 \%$ versus $0.25 \%$ in the standard DHA group. At 18 months the Mental Development Index (MDI) of the BSID-II was performed. Overall, there was no statistically significant difference between the high DHA and the standard DHA group. Although the MDI in infants with birth weights $<1250 \mathrm{~g}$ was higher, it did not reach statistical significance when adjusted for gestational age, sex, maternal education and birth order. When comparing only the girls in the highDHA and standard-DHA groups, there was a statistically significant improvement in MDI scores in the highDHA group [41]. The proportion of infants with severe developmental delay was also significantly less in the high-DHA group. Subsequently, the participants in this study were followed up at 7 years of age to assess their general intellectual ability using the Full Scale IQ of the Wechsler Abbreviated Scale of Intelligence (WASI) [42]. The researchers found no significant difference between the two groups in Full Scale, Verbal or Performance IQ [42].

While the DINO study supplemented mothers to achieve higher DHA levels in the breast milk, a randomized controlled trial by Henriksen et al. enrolled very low birth weight infants born at one of three hospitals in Norway and randomized them to receive a DHA/AA supplement or placebo for approximately 9 weeks after birth [43]. This supplement was directly added to their milk. The intervention group received supplemented human milk with a DHA concentration of $0.86 \%$ of total fatty acids, which is considered a high dose compared to the $0.3 \%$ level typical in preterm formula. At the corrected age of 6 months, the Ages and Stages Questionnaire was administered and the intervention group scored significantly higher on the problem solving section of the Ages and Stages Questionnaire compared to the control group [43]. There was also a trend toward an overall higher score in the intervention group that did not reach statistical significance (221 vs 215 points, $p$-value not given) [43]. In a study published by Almaas et al., the subjects were then followed up at 8 years of age, although no significant difference in cognitive functions was found between the two groups [44].

While the above studies demonstrated some early benefit with DHA supplementation, this benefit was not seen once the children reached school-age. A Cochrane review, updated in 2017, assessed whether giving premature infants formula milk supplemented with LCPUFA improved development, both cognitively and visually. The median concentration of DHA in formula in the included studies was $0.33 \%$ with a range of $0.15 \%$ to $1 \%$. Based on their analysis, the authors concluded that premature infants did not obtain a benefit from receiving formula milk supplemented with LCPUFAs. Importantly, however, the review stated that outcomes should be evaluated based on a yet to be determined optimal dose [45].

Studies have also evaluated the effects of DHA on the development of visual function in the premature infant. 
The DIAMOND (DHA Intake and measurement of neural development) study, though done in term infants is an important study which evaluated how DHA supplementation of infant formula, administered in one of four concentrations $(0 \%, 0.32 \%, 0.64 \%$, or $0.96 \%)$, effected visual acuity in term infants at 12 months of age [46]. This study found that infants who received any of the formula supplemented with DHA had significantly better visual evoked potential (VEP) visual acuity at 12 months of age. There was no significant difference in VEP visual acuity between DHA concentrations, however, and the authors concluded that additional DHA above $0.32 \%$ had no additional benefit [46]. In another study, performed by Smithers et al., visual responses were assessed in premature infants at two months corrected age. The infants had been randomized into either a high-DHA group receiving 1\% DHA or the standardDHA group receiving $0.3 \% \mathrm{DHA}$. This study found that infants in the high-DHA group had significantly better visual acuity at 4 months corrected age compared to infants in the standard-DHA group [47]. Molloy et al. evaluated the effects of high-DHA versus standard-DHA on visual function at school age on a subgroup of children from the DINO trial described previously [48]. They assessed the participants' visual function using the Freiburg Visual Acuity Test at 7 years old. The authors found that infants who received the human milk supplemented with high-DHA had no significant long-term benefit in their visual processing compared to infants who received standard-DHA [48].

Premature infants are deficit in DHA at birth and while short-term developmental benefits have been seen with DHA supplementation, no effects on long-term development have been shown. Because studies vary in the dosage, delivery, and length of DHA supplementation, it remains difficult to come to a decisive conclusion on DHA and cognitive outcomes. Until an optimal method for supplementing DHA to a preterm infant is found, it will continue to be a challenge to determine the true effect DHA supplementation has on the cognitive development of a premature infant.

\section{DHA and inflammation}

Premature infants are at risk for inflammatory diseases such as bronchopulmonary dysplasia (BPD) and necrotizing enterocolitis (NEC), risks which may be mitigated by DHA's anti-inflammatory properties. Atopic sensitization is also known to occur early in life and it is thought that omega-3 may help prevent this. As mentioned previously, without supplementation, DHA levels in preterm infants drop following birth [31]. Martin et al. showed an association between DHA levels in the first four weeks of life and the development of chronic lung disease (CLD) in premature infants. Lower DHA levels in these infants were significantly associated with the development of CLD. This study showed that a $1 \%$ decrease in the total fatty acid mass of DHA in the blood gave a 2.5 fold increase in the odds of developing CLD [31]. Similarly for late-onset sepsis, the authors found an association between decreased DHA concentration and an increased risk for developing late-onset sepsis. Lower AA and higher LA levels were also significantly associated with the development of late-onset sepsis in this cohort of premature infants. The authors did not find an association between mean DHA levels and IVH, NEC or ROP [31]. In addition to DHA levels, the authors also found that increased ratios of LA:DHA, AA:DHA, and n-6: n-3 were associated with CLD. A similar study was completed in Tunisia evaluating plasma DHA levels where improved control of the n-6:n-3 ratio may help prevent certain neonatal morbidities, such as RDS, sepsis and IVH in the premature infant [49]. Because infants who are born extremely premature often require TPN, a study in Greece examined the effects of various lipid emulsions on certain cytokine levels known to be proinflammatory: tumor necrosis factor (TNF)- $\alpha$, interleukin (IL)-6, and IL-8. Infants who received a lipid emulsion which contained omega-3's had significantly lower IL- 6 and IL-8 levels compared to infants receiving a typical soybean oil-based lipid emulsion [50]. Prior studies have shown an association with these cytokines and BPD in premature infants and subsequent studies have evaluated the effects of DHA on BPD in premature infants [51-53]. Another study showed that maternal fish oil supplementation of $1.5 \mathrm{~g} /$ day of $\mathrm{n}-3$ long-chain PUFA can continue to have an effect on a child's immune system up to at least two years after the supplement was given [54].

In a follow-up to the DINO trial that initially evaluated cognitive outcomes with DHA supplementation in premature infants, the authors evaluated the long-term respiratory and allergy outcomes in these infants. The infants were evaluated at 18 months for history of BPD as well as parental reports of atopic conditions such as hay fever, asthma, eczema or food allergies [52]. Of the 657 infants originally enrolled in the study 614 infants completed the 18-month follow-up, though the allergy data was incomplete, as some families did not complete these questionnaires. The authors found a statistically significant reduction in parental reported hay fever at either 12 months or 18 months in the high -DHA group compared to the standard DHA group, but no reported reductions in food allergies, eczema or asthma. The risk of developing BPD was not significantly different between the two groups but there was a significant reduction of oxygen requirement at 36 weeks in both male infants and infants with birth weights $<1250$ g. Of note, these findings should be interpreted with caution as the study was not powered to detect these differences [52]. 
Based on these previous studies suggesting that DHA may reduce the risk of BPD, the N-3 Fatty Acids for Improvement in Respiratory Outcomes (N3RO) study was developed [55]. This was a large randomized, blinded controlled trial conducted in Australia, New Zealand and Singapore that was designed to assess the effect of DHA given to premature infants delivered prior to 29 weeks on the incidence of BPD [55]. This study randomized 1273 infants to receiving either $60 \mathrm{mg} / \mathrm{kg} /$ day DHA enteral emulsion or to receive no additional DHA. There was no statistically significant difference in the development of BPD between the groups and though not significant, the DHA group actually had a higher percentage of infants who developed physiological BPD (49.1\% vs $43.9 \%, p$-value 0.07) [55]. The authors concluded that supplementing premature infants with DHA enterally did not reduce the incidence of BPD and actually may have increased the risk [55].

\section{Conclusion}

DHA is an important LCPUFA that has roles in several physiological processes including brain and visual development as well as the inflammatory process. Mothers in the United States typically consume a Western diet that is low in omega-3 fatty acids which can also lead to breast milk that has a low concentration of DHA. Premature infants, especially those born before 30 weeks, have been shown to have a deficit in DHA shortly after delivery for several reasons including foregoing third trimester DHA accretion, receiving enteral breast milk or donor milk feeds that are typically low in DHA, and having an increased risk of requiring prolonged TPN. Despite numerous studies evaluating the effects of DHA on development in the premature infant, there are still conflicting results on whether DHA actually improves the cognitive outcomes in premature infants. While short-term benefits have been seen in several studies, long-term benefits are not consistent. Future studies continue to be needed to assess the optimal DHA dosage, method of delivery (maternal supplementation, direct supplementation, IV lipid emulsions, etc.), and length of supplementation to optimize DHA intake in very premature infants.

\footnotetext{
Abbreviations

ALA: a-linolenic acid; BPD: Bronchopulmonary dysplasia; BSID: Bayley Scales of Infant Development; CLD: Chronic lung disease; DHA: Doxosahexaenoic acid; FADS: Fatty acid desaturase; IVH: Intraventricular hemorrhage; LA: Linoleic acid; LCPUFA: Long-chain polyunsaturated fatty acids; MDI: Mental Development Index; NEC: Necrotizing enterocolitis; ROP: Retinopathy of prematurity; TNF: Tumor necrosis factor; VEP: Visual evoked potential; WASI: Wechsler Abbreviated Scale of Intelligence
}

Funding

No funding obtained for this article.

Availability of data and materials

Data sharing not applicable to this article as no datasets were generated or analyzed during the current study.

\section{Disclaimer}

The views expressed in this article are those of the authors and do not reflect the official policy or position of the United States Air Force, United States Army, United States Navy, Department of Defense, or the U.S. Government.

\section{Authors' contributions \\ SS helped to draft the manuscript. CR helped to draft the manuscript. Both authors read and approved the final manuscript.}

\section{Ethics approval and consent to participate}

Not applicable

\section{Consent for publication}

Not applicable

\section{Competing interests}

The authors declare that they have no competing interests.

\section{Author details}

${ }^{1}$ Uniformed Services University of Health Sciences, 4301 Jones Bridge, Bethesda, MD 20814, USA. Walter Reed National Military Medical Center, 8901 Rockville Pike, Bethesda, MD 20814, USA.

Received: 12 July 2017 Accepted: 24 September 2017

Published online: 12 December 2017

\section{References}

1. Carlson SJ, Fallon EM, Kalish BT, Gura KM, Puder M. The role of the $\omega-3$ fatty acid DHA in the human life cycle. JPEN J Parenter Enteral Nutr. 2013;37(1): $15-22$.

2. Global Recommendations for EPA and DHA Intake (Rev 16 April 2014). http://www.goedomega3.com/index.php/files/download/304. Accessed 10 June 2017.

3. Nordgren TM, Lyden E, Anderson-Berry A, Hanson C. Omega-3 Fatty Acid Intake of Pregnant Women and Women of Childbearing Age in the United States: Potential for Deficiency? Nutrients. 2017; doi: 10.3390/nu9030197.

4. Kuipers RS, Luxwolda MF, Offringa PJ, Boersma ER, Dijck-Brouwer DA, Muskiet FA. Fetal intrauterine whole body linoleic, arachidonic and docosahexaenoic acid contents and accretion rates. Prostaglandins Leukot Essent Fat Acids. 2012:86(1-2):13-20.

5. Innis SM. Essential fatty acid transfer and fetal development. Placenta. 2005; 26(Suppl A):S70-5.

6. Storck Lindholm E, Strandvik B, Altman D, Möller A, Palme KC. Different fatty acid pattern in breast milk of obese compared to normal-weight mothers. Prostaglandins Leukot Essent Fat Acids. 2013;88(3):211-7.

7. Sanders TA. DHA status of vegetarians. Prostaglandins Leukot Essent Fat Acids. 2009:81(2-3):137-41.

8. Brenna JT, Varamini B, Jensen RG, Diersen-Schade DA, Boettcher JA, Arterburn LM. Docosahexaenoic and arachidonic acid concentrations in human breast milk worldwide. Am J Clin Nutr. 2007;85(6):1457-64.

9. Jackson $\mathrm{KH}$, Harris WS. Should there be a target level of docosahexaenoic acid in breast milk? Curr Opin Clin Nutr Metab Care. 2016;19(2):92-6.

10. Sherry CL, Oliver JS, Marriage BJ. Docosahexaenoic acid supplementation in lactating women increases breast milk and plasma docosahexaenoic acid concentrations and alters infant omega 6:3 fatty acid ratio. Prostaglandins Leukot Essent Fat Acids. 2015;95:63-9.

11. Dunstan JA, Mitoulas LR, Dixon G, Doherty DA, Hartmann PE, Simmer K, Prescott SL. The effects of fish oil supplementation in pregnancy on breast milk fatty acid composition over the course of lactation: a randomized controlled trial. Pediatr Res. 2007:62(6):689-94.

12. Kovács A, Funke S, Marosvölgyi T, Burus I, Decsi T. Fatty acids in early human milk after preterm and full-term delivery. J Pediatr Gastroenterol Nutr. 2005;41(4):454-9. 
13. Lapillonne A, Groh-Wargo S, Gonzalez CH, Uauy R. Lipid needs of preterm infants: updated recommendations. J Pediatr. 2013;162(Supple 3):S37-47.

14. Xie L, Innis SM. Genetic variants of the FADS1 FADS2 gene cluster are associated with altered (n-6) and (n-3) essential fatty acids in plasma and erythrocyte phospholipids in women during pregnancy and in breast milk during lactation. J Nutr. 2008;138(11):2222-8.

15. Moltó-Puigmartí C, Plat J, Mensink RP, Müller A, Jansen E, Zeegers MP, Thijs C. FADS1 FADS2 gene variants modify the association between fish intake and the docosahexaenoic acid proportions in human milk. Am J Clin Nutr. 2010;91(5):1368-76.

16. Baack ML, Norris AW, Yao J, Colaizy T. Long-chain polyunsaturated fatty acid levels in US donor human milk: meeting the needs of premature infants? J Perinatol. 2012;32(8):598-603.

17. Valentine CJ, Morrow G, Reisinger A, Dingess KA, Morrow AL, Rogers LK. Lactational Stage of Pasteurized Human Donor Milk Contributes to Nutrient Limitations for Infants. Nutrients. 2017; doi: 10.3390/nu9030302.

18. Valentine CJ, Morrow G, Fernandez S, Gulati P, Bartholomew D, Long D, Welty SE, Morrow AL, Rogers LK. Docosahexaenoic Acid and Amino Acid Contents in Pasteurized Donor Milk are Low for Preterm Infants. J Pediatr. 2010;157(6):906-10.

19. Valentine CJ, Morrow G, Pennell M, Morrow AL, Hodge A, Haban-Bartz A, Collins K, Rogers LK. Randomized controlled trial of docosahexaenoic acid supplementation in midwestern U.S. humanmilk donors. Breastfeed Med. 2013;8(1):86-91

20. Haggarty P. Fatty Acid Supply to the Human Fetus. Annu Rev Nutr. 2010;30: 237-55

21. Haggarty P. Placental Regulation of Fatty Acid Delivery and its Effect on Fetal Growth-A Review. Placenta. 2002; doi:10.1053/plac.2002.0791.

22. Berseth $\mathrm{CL}$, Harris CL, Wampler JL, Hoffman DR, Diersen-Schade DA. Liquid human milk fortifier significantly improves docosahexaenoic and arachidonic acid status in preterm infants. Prostaglandins Leukot Essent Fat Acids. 2014;91(3):97-103.

23. Haggarty P. Effect of placental function on fatty acid requirements during pregnancy. Eur J Clin Nutr. 2004:58(12):1559-70.

24. Lapillonne A, Jensen CL. Reevaluation of the DHA requirement for the premature infant. Prostaglandins Leukot Essent Fat Acids. 2009;81(2-3):143-50.

25. Rogers LK, Valentine CJ, Keim SA. DHA supplementation: current implications in pregnancy and childhood. Pharmacol Res. 2013;70(1):13-9.

26. Kar S, Wong M, Rogozinska $E$, Thangaratinam S. Effects of omega-3 fatty acids in prevention of early preterm delivery: a systematic review and metaanalysis of randomized studies. Eur J Gynecol Reprod Biol. 2016;198:40-6.

27. Shireman TI, Kerling EH, Gajewski BJ, Colombo J, Carlson SE. Docosahexaenoic acid supplementation (DHA) and the return on investment for pregnancy outcomes. Prostaglandins Leukot Essent Fat Acids. 2016;111:8-10.

28. Baack ML, Puumala SE, Messier SE, Pritchett DK, Harris WS. What is the relationship between gestational age and docosahexaenoic acid (DHA) and arachidonic acid (ARA) levels? Prostaglandins Leukot Essent Fat Acids. 2015; 100:5-11.

29. De Rooy L, Hamdallah H, Dyall SC. Extremely preterm infants receiving standard care receive very low levels of arachidonic and docosahexaenoic acids. Clin Nutr. 2016; https://doi.org/10.1016/j.clnu.2016.09.033.

30. Robinson DT, Carlson SE, Murthy K, Frost B, Li S, Caplan M. Docosahexaenoic and arachidonic acid levels in extremely low birth weight infants with prolongedexposure to intravenous lipids. J Pediatr. 2013;162(1): 56-61.

31. Martin CR, Dasilva DA, Cluette-Brown JE, Dimonda C, Hamill A, Bhutta AQ, Coronel E, Wilschanski M, Stephens AJ, Driscoll DF, Bistrian BR, Ware JH, Zaman MM, Freedman SD. Decreased postnatal docosahexaenoic and arachidonic acid blood levels in premature infants are associated with neonatal morbidities. J Pediatr. 2011;159(5):743-9.

32. Collins CT, Sullivan TR, McPhee AJ, Stark MJ, Makrides M, Gibson RA. A dose response randomised controlled trial of docosahexaenoic acid (DHA) in preterm infants. Prostaglandins Leukot Essent Fat Acids. 2015;99:1-6.

33. Baack ML, Puumala SE, Messier SE, Pritchett DK, Harris WS. Daily Enteral DHA Supplementation Alleviates Deficiency in Premature Infants. Lipids. 2016; 51(4):423-33.

34. Robinson DT, Caplan M, Carlson SE, Yoder R, Murthy K, Frost B. Early docosahexaenoic and arachidonic acid supplementation in extremely-lowbirth-weight infants. Pediatr Res. 2016;80(4):505-10.

35. Harris WS, Baack ML. Beyond building better brains: bridging the docosahexaenoic acid (DHA) gap of prematurity. J Perinatol. 2015;35(1):1-7.
36. Innis SM. Dietary (n-3) fatty acids and brain development. J Nutr. 2007; 137(4):855-9.

37. Janssen Cl, Kiliaan AJ. Long-chain polyunsaturated fatty acids (LCPUFA) from genesis to senescence: the influence of LCPUFA on neural development, aging, and neurodegeneration. Prog Lipid Res. 2014;53:1-17.

38. Molloy C, Doyle LW, Makrides M, Anderson PJ. Docosahexaenoic acid and visual functioning in preterm infants: a review. Neuropsychol Rev. 2012; 22(4):425-37.

39. Tam EW, Chau V, Barkovich AJ, Ferriero DM, Miller SP, Rogers EE, Grunau RE, Synnes AR, Xu D, Foong J, Brant R, Innis SM. Early postnatal docosahexaenoic acid levels and improved preterm brain development. Pediatr Res. 2016;79(5):723-30.

40. Sabel KG, Strandvik B, Petzold M, Lundqvist-Persson C. Motor, mental and behavioral developments in infancy are associated with fatty acid pattern in breast milk and plasma of premature infants. Prostaglandins Leukot Essent Fat Acids. 2012;86(4-5):183-8.

41. Makrides M, Gibson RA, McPhee AJ, Collins CT, Davis PG, Doyle LW, Simmer K, Colditz PB, Morris S, Smithers LG, Willson K, Ryan P. Neurodevelopmental outcomes of preterm infants fed high-dose docosahexaenoic acid: a randomized controlled trial. JAMA. 2009;301(2):175-82.

42. Collins $C T$, Gibson RA, Anderson PJ, McPhee AJ, Sullivan TR, Gould JF, Ryan P, Doyle LW, Davis PG, McMichael JE, French NP, Colditz PB, Simmer K, Morris SA, Makrides M. Neurodevelopmental outcomes at 7 years' corrected age in preterm infants who were fed high-dose docosahexaenoic acid to term equivalent: a follow-up of a randomised controlled trial. BMJ Open. 2015; doi: 10.1136/bmjopen-2014-007314

43. Henriksen C, Haugholt K, Lindgren M, Aurvåg AK, Rønnestad A, Grønn M, Solberg R, Moen A, Nakstad B, Berge RK, Smith L, Iversen PO, Drevon CA. Improved cognitive development among preterm infants attributable to early supplementation of human milk with docosahexaenoic acid and arachidonic acid. Pediatrics. 2008;121(6):1137-45.

44. Almaas AN, Tamnes CK, Nakstad B, Henriksen C, Walhovd KB, Fjell AM, DueTønnessen P, Drevon CA, Iversen PO. Long-chain polyunsaturated fatty acids and cognition in VLBW infants at 8 years: an RCT. Pediatrics. 2015;135(6):972-80.

45. Moon K, Rao SC, Schulzke SM, Patole SK, Simmer K. Longchain polyunsaturated fatty acid supplementation in preterm infants. In: Cochrane Neonatal Group Cochrane Database of Systematic Reviews; 2017, Issue 2. Art. No.: CD000375. doi: 10.1003/14651858.CD000375.pub5.

46. Birch EE, Carlson SE, Hoffman DR, Fitzgerald-Gustafson KM, Fu VL, Drover JR, Castañeda YS, Minns L, Wheaton DK, Mundy D, Marunycz J, Diersen-Schade DA. The DIAMOND (DHA Intake And Measurement Of Neural Development) Study: a double-masked, randomized controlled clinical trial of the maturation of infant visual acuity as a function of the dietary level of docosahexaenoic acid. Am J Clin Nutr. 2010;91(4):848-59.

47. Smithers LG, Gibson RA, McPhee A, Makrides M. Higher dose of docosahexaenoic acid in the neonate improves visual acuity of preterm infants: results of a randomized controlled trial. Am J Clin Nutr. 2008;88:1049-56.

48. Molloy CS, Stokes S, Makrides M, Collins CT, Anderson PJ, Doyle LW. Longterm effect of high-dose supplementation with DHA on visual function at school age in children born at $<33$ wk gestational age: results from a follow-up of a randomized controlled trial. Am J Clin Nutr. 2016;103:268-75.

49. Fares S, Sethom M, Kacem S, Khouaja-Mokrani C, Feki M, Kaabachi N. Plasma arachidonic and docosahexaenoic acids in Tunisian very low birth weight infants: status and association with selected neonatal morbidities. J Health Popul Nutr. 2015; doi: 10.1186/s41043-015-0011-3.

50. Skouroliakou M, Konstantinou D, Agakidis C, Kaliora A, Kalogeropoulos N, Massara P, Antoniadi M, Panagiotakos D, Karagiozoglou-Lampoudi T. Parenteral MCT/ $\omega-3$ Polyunsaturated Fatty Acid-Enriched Intravenous Fat Emulsion Is Associated With Cytokine and Fatty Acid Profiles Consistent With Attenuated Inflammatory Response in Preterm Neonates: A Randomized. Double Blind Clin Trial Nutr Clin Pract. 2016:31(2):235-44.

51. De Dooy JJ, Mahieu LM, Van Bever HP. The role of inflammation in the development of chronic lung disease in neonates. Eur J Pediatr. 2001;160(8): 457-63.

52. Manley BJ, Makrides M, Collins $C T$, McPhee AJ, Gibson RA, Ryan P, Sullivan TR, Davis PG, DINO Steering Committee. High-dose docosahexaenoic acid supplementation of preterm infants: respiratory and allergy outcomes. Pediatrics. 2011;128(1):e71-7.

53. Collins CT, Gibson RA, Makrides M, McPhee AJ, Sullivan TR, Davis PG, Thio M, Simmer K, Rajadurai VS, N3RO Investigative Team. The N3RO trial: a randomised controlled trial of docosahexaenoic acid to 
reducebronchopulmonary dysplasia in preterm infants $<29$ weeks' gestation. BMC Pediatr. 2016; doi: 10.1186/s12887-016-0611-0.

54. Lauritzen L, Kjaer TM, Fruekilde MB, Michaelsen KF, Frøkiaer H. Fish oil supplementation of lactating mothers affects cytokine production in 2 1/2year-old children. Lipids. 2005;40(7):669-76.

55. Collins CT, Makrides M, McPhee AJ, Sullivan TR, Davis PG, Thio M, Simmer K, Rajadurai VS, Travadi J, Berry MJ, Liley HG, Opie GF, Tan K, Lui K, Morris SA, Stack J, Stark MJ, Chua MC, Jayagobi PA, Holberton J, Bolisetty S, Callander IR, Harris DL, Gibson RA. Docosahexaenoic Acid and Bronchopulmonary Dysplasia in Preterm Infants. N Engl J Med. 2017;376(13):1245-55.

Submit your next manuscript to BioMed Central and we will help you at every step:

- We accept pre-submission inquiries

- Our selector tool helps you to find the most relevant journal

- We provide round the clock customer support

- Convenient online submission

- Thorough peer review

- Inclusion in PubMed and all major indexing services

- Maximum visibility for your research

Submit your manuscript at www.biomedcentral.com/submit
Biomed Central 